\title{
Morality and competence in person- and self-perception
}

\author{
Bogdan Wojciszke \\ Polish Academy of Sciences, Warsaw, Poland
}

\begin{abstract}
Morality and competence are posited to constitute two basic kinds of content in person- and self-perception. Moral content dominates person-perception because it typically has a direct and unconditional bearing on the well-being of other people surrounding the person who is described by the trait (including the perceiver). Competence dominates self-perception because it has a direct bearing on the well-being of the perceiver. A comprehensive research programme is reviewed showing that morality of others matters to the perceiver to a much higher degree than his/her competence. When forming global evaluations of others, the perceiver is more interested in their moral than competence qualities, construes their behaviour in moral terms, and his or her impressions and emotional responses are more strongly based on morality than competence considerations. Just the opposite is true for selfperception and self-attitudes. Own behaviours are construed more readily in competence than moral terms, and own competence influences self-evaluations and emotional responses to a higher degree than own morality.
\end{abstract}

Person-perception and self-perception processes are strongly saturated with evaluations and other affective processes. Evaluative responses are ubiquitous, primary, and partially independent of access to stimuli descriptive meaning. Frequently, these responses are also effortless, unconscious, very fast, unintentional, and automatically related to behavioural tendencies (cf. Bargh, 1997; Dijksterhuis \& Bargh, 2001; Zajonc, 2000). Most probably, the ubiquity and prominence of evaluation is a consequence of the basic function of social cognition - discerning between beneficial and harmful social objects or environments in the service of approach vs avoidance behaviour. All organisms have at least one mechanism for differentiating agreeable from

Correspondence should be addressed to Bogdan Wojciszke, Institute of Psychology, Polish Academy of Sciences, ul. Chodakowska 19/31, 03-851 Warszawa, Poland. Email: bogdan@psychpan.waw.pl

Numerous studies reported in this chapter were supported by Komitet Badan Naukowych (Poland) and the Alexander von Humboldt Stiftung (Germany). I would like to thank Wiesiek Baryla for many discussions and Miles Hewstone, Paul Van Lange, Guido Peeters, and an anonymous reviewer for helpful comments.

(C) 2005 European Association of Experimental Social Psychology

http://www.tandf.co.uk/journals/pp/10463283.html

DOI: $10.1080 / 10463280500229619$ 
adverse environments and humans have many, including evaluative processes like attitudinal responses (Caccioppo, Gardner, \& Berntson, 1997) and global impressions of others. Social information processing is, of course, highly flexible and depends on the perceiver's current goals. Nevertheless, the approach-avoidance dimension looms in every nook and cranny searched by modern social cognition students, and "evaluation is a pervasive and dominant response for most people across the many situations and objects they encounter' (Jarvis \& Petty, 1996, p. 173).

Using the computer metaphor of mind, one may say that forming global evaluative impressions serves as a default option in the person-perception process. Evaluative impressions of encountered persons are routinely formed, apparently without effort and specific purposes. Evaluation may be based on various criteria (depending on the perceiver's specific goals) but the basic and most frequently used is probably the criterion of self-interest broadly defined as preserving the perceiver's immediate well-being. If so, evaluation should be strongly underlain by concepts instrumental in locating others (target persons) on the approach-avoidance dimension. Peeters (1992) called such concepts other-profitable traits, i.e., traits that have a direct and unconditional bearing on the well-being of other people surrounding the trait possessor (the perceiver included), such as kind, honest, or aggressive. Peeters discerned them from self-profitable traits, which have a direct and unconditional bearing for trait possessors themselves, such as intelligence or inefficiency (whatever one does, it is better to do it efficiently; others may gain or lose from this efficiency depending on the goals of the trait possessor).

These two dimensions determine global favourability of traits, as shown in a study where a pool of 200 trait names was rated by various groups of judges for several criteria, such as controllability, behavioural range, temporal and cross-situational stability, etc. (Wojciszke, Dowhyluk, \& Jaworski, 1998b). Out of a dozen possible criteria only two predicted reliably the global favourability of traits in a simultaneous regression analysis: the otherprofitability (the degree to which a trait was beneficial or harmful to other people surrounding the trait possessor, $\beta=.58$ ) and the self-profitability (the degree to which a trait was beneficial or harmful to the trait possessor, $\beta=.42$ ). Moreover, these two features of traits together explained nearly all the variance in favourability ratings (adjusted $R^{2}$ was .97). Benefits and costs brought by traits to their possessors and persons who interact with them seem to practically exhaust antecedents of the trait valence.

\section{PROMINENCE OF MORALITY AND COMPETENCE IN PERSON-PERCEPTION}

The theoretical distinction between other- versus self-profitable traits overlaps substantially with two types of information content involved in person- 
perception - those of morality and competence. Moral traits are otherprofitable in the sense that they capture whether the goals of an acting person are beneficial or harmful to other people. On the other hand, competence (efficiency of goal attainment) is self-profitable because it is directly and unconditionally rewarding for a person who shows this quality rather than for others. Similarly, incompetence is unconditionally detrimental to the actor rather than to others (others may also lose from the actor's incompetence, but on the condition that their outcomes are dependent on his or her acts).

Several lines of research show the paramount role of morality (M) and competence $(\mathrm{C})$ in person-perception and global evaluations. In one study we asked our participants for recollection of real-life episodes from their personal past in which they had come to a clear-cut evaluative conclusion about another person or themselves (Wojciszke, 1994, Study 1). The participants provided a description of each episode (what they or another person had done), then showed how positive or negative their global evaluation (of self or another person) was, and, finally, gave a rationale for their evaluation. This enabled independent raters to estimate how much each of the evaluations was based on morality and competence. Content analysis of over 1000 episodes showed that in three-quarters of them the evaluative impression was based on M- or C-related considerations, suggesting that when an interpersonal episode is important enough to instigate a clear evaluation, it is usually because of morality, competence, or both. In another study we asked participants for global evaluations of 20 well-known persons from their social environment and description of their $\mathrm{M}$ and $\mathrm{C}$ traits (Wojciszke, Bazinska, \& Jaworski, 1998a, Study 3). On average, these two sorts of trait ascription explained a large majority $(82 \%)$ of the variance of global impressions. The same was true for the perception of participants' supervisors in different organisations (described later in Table 4).

Morality and competence also constitute two separate and basic clusters of traits in the perception of leaders (Chemers, 2001), and these clusters define the two classical styles of organisational leadership: relation-oriented and task-oriented. The two trait types appear frequently in voters' openended commentaries on political candidates in various countries (e.g. the US; Kinder \& Sears, 1985: or Poland; Wojciszke \& Klusek, 1996). They also constitute two basic clusters in the perception of political leaders, and president evaluations along these two dimensions are much better predictors of president approval than purely evaluative global attitude towards the president (Wojciszke \& Klusek, 1996).

Phalet and Poppe (1997) extended the morality-competence distinction to the area of group perception. Studying national and ethnic stereotypes among six eastern-European countries, these authors showed that $\mathrm{C}$ and $\mathrm{M}$ constitute a dual evaluative hierarchy which was replicated over six countries both for ingroup and outgroup perspectives. Competence and morality not 
only emerged as distinct dimensions of stereotypes, they also explained the perceived distances between national groups better than a purely evaluative one-dimensional ordering typically used to analyse distance in multiplegroup systems. These ideas acquired a more general flavour in the work of Fiske and her colleagues on the stereotype content model (Fiske, Cuddy, Glick \& Xu, 2002; Fiske, Xu, Cuddy \& Glick, 1999). Using various samples and stereotyped groups, these authors showed that stereotype content universally involves two basic dimensions which they called warmth and competence. The perception of groups as competent or incompetent follows from their high or low position in the status - power hierarchy and justifies the existing social order. Perception of groups as warm results from their deference and benevolence, that is, their lack of intention to compete against the perceivers' own group (which is very close to what is understood here as perceived morality). These two dimensions are independent, which speaks against general antipathy as the basis of stereotyping, because many groups are perceived as both warm and incompetent (paternalistic stereotype, e.g., of housewives) or as highly competent but not warm (envious stereotypes, e.g., of feminists). The stereotype content model builds on a social structural hypothesis assuming that stereotypes result from structural relations between groups in a way that justifies and perpetuates the status quo, giving legitimacy to the social system (Jost \& Hunyady, 2002).

\section{EXPLANATIONS OF MORALITY VERSUS COMPETENCE DIFFERENCES}

A substantial amount of research coming from diverse areas of psychology suggests that generally "bad is stronger than good" (Baumeister, Bratslavsky, Finkenauer, \& Vohs, 2001) and people show a general negativity bias (Rozin \& Royzman, 2001). Bad events, outcomes, and pieces of information exert a stronger effect on people's responses than good ones, even when the positives and negatives are balanced for extremity. ${ }^{1}$ In impression-formation research, it is regularly found that when equal amounts of positive and negative information about the target person are

\footnotetext{
${ }^{1}$ The negativity effect discussed in this chapter refers to perceptions and evaluations based on relevant (and incongruent) information already possessed by the perceiver. So, this negativity effect is an a posteriori bias, which should be discerned from an a priori positivity bias. The latter is called the Polyanna principle (Kanouse \& Hanson, 1972) and means a generalised expectation that persons, the future, or personal and social events will appear positive rather than negative. Such expectations are generally formulated by perceivers who still lack the relevant information and hence assume positivity by default (cf. Peeters \& Czapinski, 1990). The difference between negativity and positivity bias was nicely captured by a Polish philosopher Tatarkiewicz (1976) in his remark on divergent foundations of realism and optimism: Whereas realism is based on observation of facts, optimism is derived from theories (i.e. expectations and hopes).
} 
integrated, a generally negative impression arises, especially when the input information is extreme and perceived as valid. This negativity effect is typical for situations where the mixed information about target persons pertains solely or partially to morality (see Peeters \& Czapinski, 1990; Skowronski \& Carlston, 1989, for reviews). However, when the integrated information pertains solely to competence, a positivity effect is found (Brycz \& Wojciszke, 1992; Kubicka-Daab, 1989; Skowronski \& Carlston, 1987, 1989; Wojciszke, Brycz, \& Borkenau, 1993).

These asymmetries in the integration of mixed information in the $\mathrm{M}$ and $\mathrm{C}$ domain have been explained in two ways: Cognitive (stressing the differential structure of $\mathrm{M}$ and $\mathrm{C}$ categories) and motivational (stressing the differential role played by the two types of behaviour categorisation in locating other people on the approach-avoidance dimension). These two accounts of $\mathrm{M}-\mathrm{C}$ differences are mutually supportive rather than exclusive, but they lead to divergent expectations concerning both the negativitypositivity biases and other areas of person-perception.

\section{Cognitive explanations}

Two well-developed explanations of negativity effect in the $\mathrm{M}$ domain and positivity effect in the $\mathrm{C}$ domain are the schematic model of attribution (Reeder \& Brewer, 1979; Reeder, Pryor, \& Wojciszke, 1992) and the cuediagnosticity model of impression formation (Skowronski \& Carlston, 1987). Both theories assume that people infer personality traits from others' actions, and that in the $\mathrm{M}$ domain negative information is more decisive than positive information, while the opposite is true in the $\mathrm{C}$ domain.

In Reeder's formulation this is because of differential expectations about trait-behaviour relations which people hold in the two domains. Perceivers assume that moral people behave in moral but not immoral ways, although immoral people can behave both in immoral and moral ways because the latter are socially demanded and rewarded. In effect, moral behaviours are not informative about the underlying traits, because the former may reflect not only traits but also various situational pressures. The opposite is true for competence. Everybody can fail or behave in incompetent ways (due to task difficulty or lack of motivation), but only persons of high ability are capable of competent actions. In effect, in the $\mathrm{C}$ domain, successes and positives in general are more informative than negatives.

In Skowronski's formulation the difference is due to asymmetrical diagnosticity of positive and negative behaviours in the two domains. In the $\mathrm{M}$ domain, negatives have higher diagnostic value than positives because they better discern between moral and immoral persons. In the $\mathrm{C}$ domain, positives are more exclusive than negatives, which renders the former more diagnostic for decisions about whether a person belongs to the "competent" 
category or not. These two cognitive accounts of negativity-positivity effects in the $\mathrm{M}$ and $\mathrm{C}$ domain are highly convergent and have been confirmed in extensive research using various dependent measures (cf. Reeder, 1993; Skowronski, 2002).

\section{Motivational explanations}

The differentiation of behavioural information in terms of $\mathrm{M}$ - and Crelatedness refers to its descriptive meaning: Which traits, goals, or other qualities of actors does the information indicate? As mentioned before, behavioural information also has an evaluative meaning referring to observers' subjective responses towards the targets (are they good or bad, friendly or dangerous, should they be approached or avoided?). An extensive series of studies showed that perceivers: (a) interpret the target's behaviour in terms of descriptive personality traits exemplified by the behaviour, (b) extract the evaluative meaning of that behaviour in order to form a general evaluative impression of the target person, and (c) store the two meanings (descriptive and evaluative) separately in their memory (Srull \& Wyer, 1989; Wyer \& Srull, 1986). The descriptive and evaluative meanings of behavioural information seem to be stored separately and processed in partially different ways. Moreover, their processing serves different functions: The descriptive meaning is processed to categorise people and to accurately infer their traits and intentions, whereas the evaluative meaning is processed to direct the perceiver's responses concerning approach or avoidance of the target person.

The two meanings are related and interdependent, for example the individual's approach-avoidance is partially decided on the basis of characteristics attributed by him or her to the target. Still, the theoretical analysis of positive and negative behaviours as approach-avoidance cues leads to predictions that seem not to follow from their status as descriptive cues that indicate traits. The negativity effect - that is, to evaluate a target person endowed with both positive and negative characteristics to be generally undesirable - reflects a risk-avoidance strategy in interpersonal relations. Negative responses towards such persons lead to avoidance of any further contacts with them in order to avoid the anticipated harmful outcomes of those contacts. In effect, any possible beneficial outcomes of these contacts are lost as well, which is the price for safety. Such a riskavoidance strategy seems to be most appropriate if the potentially harmful consequences of contacts with an ambivalent person are severe, because the more negative an attribute, the greater the chance of irreversibility of harm inflicted by this attribute (Peeters \& Czapinski, 1990). Thus a tendency towards negativity may be expected if the mixed information that is available about a target person is evaluatively extreme. 
However, if individuals used only the risk-avoidance strategy to cope with their social environment, their well-being in interpersonal relations would be put in jeopardy. Although this strategy protects against potential danger, it is also conservative in nature and narrows the number of partners in social interactions, for it blocks the initiation and development of new relationships. After all, because most people we meet have positive as well as negative qualities, they would eventually be rejected if risk-avoidance were the only decisive factor. Thus, in order to maintain and expand their contacts with other persons, individuals sometimes have to integrate mixed information to the effect that the other person is positively evaluated and therefore approached. This somewhat risky strategy is most reasonable if its possible negative consequences are mild rather than severe, because mild discomforts are easier to endure, to reverse, or to compensate by possible benefits. Thus one may expect a positivity bias to occur if moderately positive and moderately negative information about the same target person is available.

These predictions were tested in an experiment where participants received discrepant (both positive and negative) behavioural information about a target person's specific M- or C-related trait, and the information was either moderate or extreme in evaluative implications (Wojciszke et al., 1993). The participants rated the specific traits implicated by the target's behaviour as well as their global evaluations of the target. There were three C-related descriptions (i.e., incongruent sets of behavioural acts referring to either intelligence, or courage, or will-power) and three M-related ones (referring to either honesty, or fairness, or loyalty), which served as withinparticipants replications (i.e., each participant responded to six target persons). As illustrated in Table 1, the negativity effect in the moral domain (averaged over three trait/target replications) appeared strong for extremely evaluated information, but weak or nonexistent for moderately evaluated information. In contrast, the positivity effect in the competence domain was stronger for moderately than for extremely evaluated information. Thus, when effects postulated by the two discussed theories (referring to the asymmetrical diagnosticity or evaluative extremity of the integrated information) both favour positive impressions, a clear positivity bias emerges. In contrast, when both influences favour negative impressions, a clear negativity bias is found. However, if the moral content of integrated information invites negativity, whereas its low evaluative extremity invites positivity (or the other way round), the two influences work in opposite directions and the impressions tend to be neutral.

Wojciszke et al. (1993) argued that both main effects illustrated in Table 1, that of content and that of extremity, reflect the goals and interests of perceivers. Let us first consider the effects of content. Perceivers are usually less affected by a lack of competence in others than by their immoral behaviour. If others are competent, it's fine because they can help others or 
TABLE 1

Positivity and negativity biases in trait inferences and global evaluations as a function of the content and evaluative extremity of the integrated information

\begin{tabular}{lccc}
\hline & \multicolumn{2}{c}{ Content domain } & \multirow{2}{*}{ Mean } \\
\cline { 2 - 3 } Evaluative extremity & \multicolumn{2}{c}{ Competence } & Morality \\
\hline \multirow{2}{*}{ Moderate } & \multicolumn{2}{c}{ Trait inferences } & $0.63^{* * *}$ \\
Extreme & $1.01^{* * *}$ & 0.25 & $-0.32^{* *}$ \\
Mean & $0.33^{* *}$ & $-0.94^{* *}$ & \\
Moderate & $0.67^{* * *}$ & $-0.34^{* *}$ & $0.64^{* * *}$ \\
Extreme & \multicolumn{2}{c}{ Global evaluations } & $-0.38^{* *}$ \\
Mean & $1.37^{* * *}$ & -0.09 & \\
\hline
\end{tabular}

The neutral value is 0.00 for all measures. ${ }^{*} p<.05 ;{ }^{* *} p<.01 ;{ }^{* * *} p<.001$ : Means significantly different from zero ( $t$ tests). From Wojciszke et al. (1993) with permission (c) American Psychological Association.

be asked for advice. If they are not competent, this does not interfere very much with perceivers' interests because one can usually turn to someone else. Competent behaviour may therefore be weighted more strongly than incompetent behaviour. In contrast, perceivers are more affected by the immoral than by the moral behaviour of other persons because others' immoral behaviours may threaten the perceivers' well-being, property, or even their lives, without giving them the chance to avoid or to escape the perpetrator. This may be the reason why immoral behaviour is weighted more strongly than moral behaviour in information integration.

Generally speaking, $\mathrm{M}$ - and C-related qualities are differently relevant for self-interest according to the actor's and observer's perspectives and the two types of information have diverging evaluative implications for trait possessors (actors) and other people who surround them (observers) (cf. Peeters, 1992). This is because moral acts refer directly to the dimension of other-concern, while competence taps directly the dimension of selfconcern - to borrow terms from social-value orientation theorists (Van Lange, 2000; Van Lange \& Kuhlman, 1994). Moral acts have inherent interpersonal consequences and they are spontaneously judged by how they affect other people, not their perpetrators (Vonk, 1999). Usually, observers directly benefit from an actor's honesty, just as they are harmed by his or her cheating, either actually (when they are recipients of the action in question) or potentially (by anticipation of what would happen to them if they interacted with the actor). For the actor, however, his/her own honesty is more ambiguous as it may be beneficial to him/her in the long term due to reciprocity and fostering social trust, but it may be costly as well, because 
honesty usually means curbing short-term interests of the actor or leaving him/her vulnerable to exploitation by (dishonest) interaction partners. On the other hand, competence is always directly beneficial to the actor, just as incompetence (e.g., stupidity) is immediately harmful to him/her. Other persons (observers) may also be affected by the actor's competence but only on the condition that their fate depends on the actor's conduct, and this competence may bring either benefits or harms, which depends on the actor's intentions. If the actor has decided to help an observer, the latter will benefit from competence of the former (the help will be more efficient). If, however, the actor intends harm, his/her incompetence will actually be beneficial to the observer (the wrongdoing will be less harmful because inefficient). Indeed, in some conditions people prefer incompetence in others, for example, if others are enemies (Peeters, 1992) or provide opportunities for exploitation (Van Lange \& Kuhlman, 1994).

It is well known that goals are capable of directing cognition (cf. Moskowitz, 2005). In so far as self-interest is a chronically accessible goal, which is differently served by $\mathrm{M}$ and $\mathrm{C}$ qualities in the actor vs observer perspective (as discussed above), two propositions may be advanced. First, morality of others is more important than their competence to observers. Second, own competence is more important than morality to actors. These propositions have numerous and far-reaching consequences studied in the research programme reported here. Because we believe that the idea of selfvs other-profitability offers a parsimonious account of various regularities found in this programme, let me start from hypotheses referring to the profitability notion.

Moral categories are more important to other-interest, which leads to a hypothesis that $\mathrm{M}$ traits are more other-profitable but less self-profitable than $\mathrm{C}$ traits. Competence-related categories are more pertinent to selfinterest. Both these hypotheses were supported in an already mentioned study in which numerous trait names were rated for various parameters (Wojciszke et al., 1998b). Specifically, we elicited about 20 negative or positive moral traits (e.g., deceitful, dishonest, fair, and honest) as well as 20 negative or positive competence-related traits (e.g., unintelligent, disorganised, efficient, and gifted). ${ }^{2}$ A group of 15 participants rated each of these

\footnotetext{
${ }^{2}$ Morality-relatedness of each of the 200 trait names was rated by 19 participants on a scale ranging from 0 (not related to morality at all) to 10 (very strongly related to morality). M-related traits were defined as those that pertained to breaking or maintenance of moral rules. Competence-relatedness was rated by another group of 19 participants on a similar $0-10$ scale. C-related traits were defined as those that enabled people to efficiently attain their goals or obstruct the goal attainment (whatever the goals were). Both groups of raters appeared highly consistent (Cronbach's alphas were .92 and .97). In all studies reported, a trait was defined as M-related if the average rating of its M-relatedness was higher than 6.0 and ratings of its $\mathrm{C}$ relatedness was lower than 4.0. Similar minimal conditions applied to C-related traits.
} 


\section{4}

traits for self-profitability on a scale from -5 (very harmful or disadvantageous to a person who has the trait) to 0 (neutral) to 5 (very profitable or advantageous to a person who has the trait). Another group of 15 participants rated each trait for other-profitability on a similar -5 to 5 scale. These ratings were subjected to 2 (morality vs competence) $\times 2$ (negative vs positive) $\times 2$ (self vs other-profitability) ANOVA, which yielded a highly significant interaction of all three variables. As can be seen in Figure 1, moral traits appeared more extreme in their other- than self-profitability, whereas competence-related traits were rated as more extreme in self- than other-profitability. Virtually all expected simple effects (illustrated in Figure 1 with pairs of adhering columns) appeared significant, for example moral traits were rated as more advantageous for others than self, traits showing competence appeared more profitable for the self than others and so on.

In their already mentioned study on national stereotypes, Phalet and Poppe (1997) obtained similar effects on the group level. These authors asked participants from six European countries to rate several traits for ingroup desirability (e.g., Poles answered the question How desirable or undesirable would it be for Poles if all Poles had the attributes listed below?) and outgroup desirability (e.g., Poles answered the question How desirable or undesirable would it be for Poles if all Germans had the attributes listed below?). The perceived desirability of ingroup attributes appeared primarily

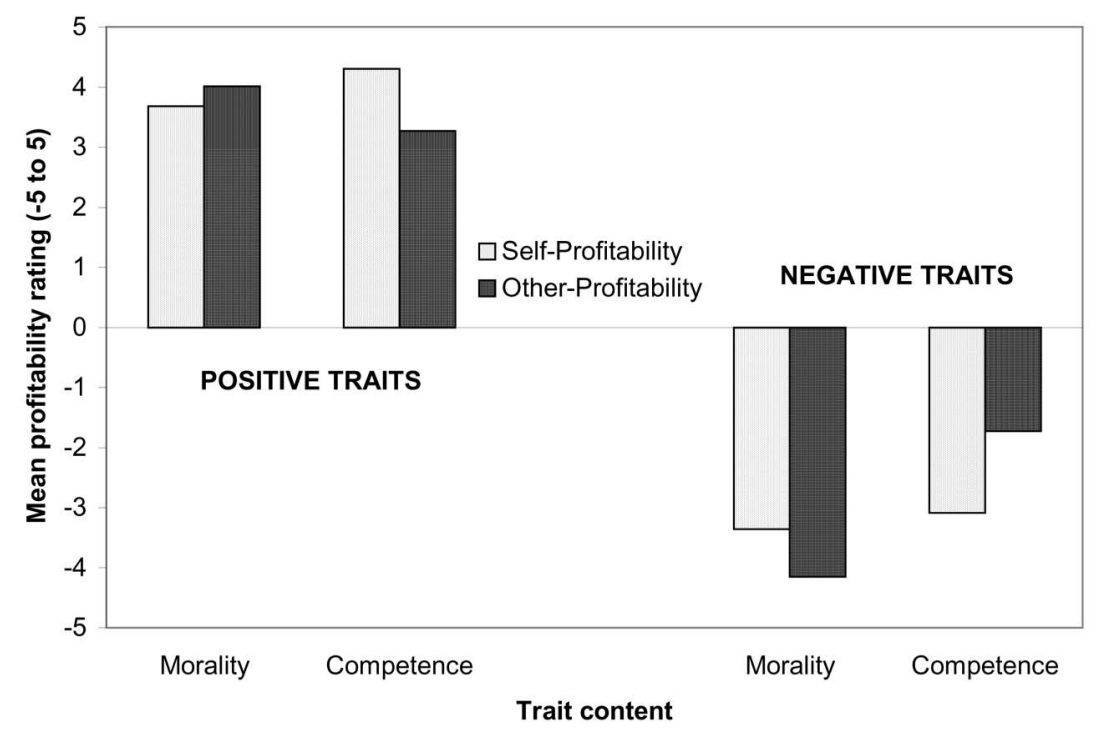

Figure 1. Self- and other-profitability ratings of the negative and positive moral and competence-related traits (Wojciszke et al., 1998b). 
competence-based, while desirability perceptions of outgroup attributes were mostly morality-based.

\section{DIFFERENCES IN PROCESSING INFORMATION ON MORALITY AND COMPETENCE}

A good deal of research suggests that human behaviour is frequently, if not typically, amenable to different interpretations. Most behavioural acts are instances of more than one trait category (Borkenau, 1986) and identical behavioural information may result in different inferences depending on the content of primed or co-occurring information (cf. Moskowitz, 2005), as well as on the behaviour features on which the perceiver focuses. Inferences of $\mathrm{M}$ and $\mathrm{C}$ traits are based on different features of an observed action. Morality refers to the interpersonal content of goals of an acting personwhether the goals are beneficial to other people and maintain moral norms, or are harmful to others and transgress the norms. Competence refers to the efficiency in goal attainment - whether the goals are effectively reached or remain unattained.

These two features of actions are clearly orthogonal: Both moral and immoral actions can be successful, indicating competence of their actor, but both types of goals can also remain unattained, thus showing the actor's incompetence. This suggests a $2 \times 2$ classification of actions with respect to their construal in M- and C-related terms, as illustrated in Table 2. The first type of action is virtuous success, where the action goal is moral and successfully achieved (e.g., rescuing a drowning person); the second is virtuous failure, where the actor aims at a moral goal but fails to achieve it (e.g., failing in one's attempt to rescue a drowning person); the third is sinful success, where the goal is immoral and successfully achieved (e.g., undetected cheating at an exam); and finally comes sinful failure, where the actor fails to achieve an intended immoral goal (e.g., being caught cheating in an exam).

TABLE 2

The independence of competence and moral interpretation of behaviour and the resulting fourfold classification of actions

\begin{tabular}{llc}
\hline & \multicolumn{2}{c}{ Moral interpretation } \\
\cline { 2 - 3 } Competence interpretation & Positive & Negative \\
\hline Positive & Virtuous & Sinful \\
& success & success \\
Negative & Virtuous & Sinful \\
& failure & failure \\
\hline
\end{tabular}

From Wojciszke (1994) with permission @ American Psychological Associations. 
Although each type of action is potentially interpretable in both $\mathrm{M}$ and $\mathrm{C}$ terms, people actually tend to interpret each action in a single way: either in terms of morality or in terms of competence. Strong negative correlations between the two construals of the same behaviour were found in various studies of this programme (with values ranging from -.54 to -.87 over content replications; Wojciszke 1994, Study 2; Wojciszke 1997, Study 2). Interestingly, these correlations hold not only when the two sorts of construal are incongruent in their evaluative implications (i.e., for virtuous failure and sinful success, where one of the interpretations leads to positive but another to negative evaluation), but also when the two are evaluatively congruent (i.e., virtuous success and sinful failure, where both interpretations lead to similar evaluation). This suggests that the negative correlation between the two sorts of behaviour construal cannot be explained in terms of the avoidance of evaluative inconsistency. Rather, behaviour construal seems to be a process of looking for a frame of reference that tends to be singular and suppresses alternative frames of reference when applied. This interpretation is strengthened by results showing that subliminal priming of moral categories inhibits the use of C-traits, whereas priming of competence categories leads to inhibition in the use of M-traits in answering queries about the meaning of doubly interpretable behavioural acts (Jaworski \& Drogosz, 1998).

\section{Information gathering and construal}

The assumption of $\mathrm{M}$ versus $\mathrm{C}$ differential bearing on the perceiver's selfinterest leads to a prediction that perception of others should be dominated by concern with M- rather than C-related information. This dominance has been shown in several studies tapping various phases of person-perception processes. In one of the studies we elicited from our participants their most accessible person-descriptors (" 10 traits which you personally think are most important in others and which draw your attention more than other traits") and then had the descriptors rated for their M- and C-relatedness (Wojciszke et al., 1998a, Study 1). Chronically accessible descriptors of others appeared to be related to $\mathrm{M}$ rather than $\mathrm{C}$. The 10 traits listed most frequently were: sincere, honest, cheerful, tolerant, loyal, intelligent, truthful, unselfish, reliable, kind (thus only two of them were clearly related to $\mathrm{C}$, i.e., intelligent and reliable). Moreover, a subsample of the participants was also presented with behavioural descriptions construable both in $\mathrm{M}$ and $\mathrm{C}$ traits, which enabled us to measure the degree to which each of the provided descriptions was actually construed in $\mathrm{M}$ and $\mathrm{C}$ terms (using a method described below). As expected, the higher chronic accessibility of $\mathrm{M}$ trait-descriptors, the higher was the tendency to construe the ambiguous behaviour as moral-immoral $(r=.56)$, and the higher chronic accessibility 
of C-trait descriptors, the higher was the tendency to construe the provided behaviour as competent-incompetent $(r=.60)$.

A person-perception process typically starts either with an active search for information about the perceived person or with a more passive choice among different items of incoming information. Whether active or passive, the outset of person-perception involves a selection of information upon which the impression will be based. The idea that perception of others is dominated by morality suggests that when selecting information, perceivers should be generally more interested in M- than C-related qualities of the perceived person. Generally, however, does not mean always. Human information processing is highly flexible and dependent on the perceiver's cognitive and motivational goals (cf. Martin, Strack, \& Stapel, 2001). When the perceiver's goal pertains to the target's competence (as in the course of employment decisions) the former will be highly tuned to information on the latter's abilities. In a similar vein, when the perceiver is for some reason or another interested in the target's integrity, the latter's morality will draw his or her attention.

The dominance of morality hypothesis suggests a high interest in the target's morality even when this concern is not fuelled by current specific goals of the perceiver. To test this hypothesis we devised a simple traitselection task in which participants chose traits they considered important to accomplishing one of the three goals: (1) to form a global evaluative opinion of a person (impression goal); (2) to decide whether they could confide in a person (M-relevant goal); (3) to decide whether they would select a person for the role of a negotiator in a complex labour dispute (C-relevant goal). Participants were presented with a list of 24 traits possibly characterising a target person and asked to select traits they would like to be informed about in order to pursue their relevant impression goal. All these traits were positive and eight of them pertained to $\mathrm{M}$ but not $\mathrm{C}$ (e.g., fair, helpful, honest), eight others pertained to $\mathrm{C}$ but not $\mathrm{M}$ (e.g., clever, creative, efficient), and eight buffer traits pertained neither to C nor M. As can be seen in Table 3, participants chose a greater number of the M- than Crelated traits under the confiding goal and the opposite was true under the negotiation goal. Most interestingly, the participants were also much more interested in gathering information on moral- than competence-related traits under the goal of forming global impressions of others.

As predicted, then, impression formation instigated greater interest in obtaining information on morality than competence of the target person, even when this concern was not fuelled by current specific goals of the perceivers. The greater interest in $\mathrm{M}$ traits was not driven by their higher favourability because the average favourability ratings of the eight $\mathrm{M}$ and eight $\mathrm{C}$ traits used in this study were virtually identical and invariably high (and the same was true for other studies reported in this chapter). 
TABLE 3

The number of moral- and competence-related traits selected under different goals (conditions) in order to make valid impressions

\begin{tabular}{|c|c|c|c|}
\hline \multirow[b]{2}{*}{ Goal/condition } & \multicolumn{2}{|c|}{ Domain } & \multirow{2}{*}{$\begin{array}{c}t \\
(d f=99)\end{array}$} \\
\hline & Morality & Competence & \\
\hline Personal secret & 4.48 & 1.50 & 12.55 \\
\hline Negotiator & 2.36 & 4.62 & 8.71 \\
\hline Impression & 4.33 & 2.23 & 7.62 \\
\hline
\end{tabular}

All $t$ tests are significant at $p<.001$.

From Wojciszke et al. (1998a, Study 2).

Another prediction of the self-interest model is that when an action is construable in terms of both $\mathrm{M}$ and $\mathrm{C}$ categories, actors tend to construe the action in $\mathrm{C}$ terms but observers tend to interpret it in $\mathrm{M}$ terms. This hypothesis is based on the idea that the actor-observer difference in perspective results in a differential accessibility and applicability of $\mathrm{C}$ and $\mathrm{M}$ categories. Entertaining the actor position, individuals strive to achieve their currently pursued goals and are preoccupied with themselves as active agents. Among the mechanisms of personal agency, people's self-efficacy beliefs play a central role in determining motivation and action, as shown by Bandura and his colleagues in a long line research (Bandura, 1997; Maddux $\&$ Gosselin, 2003). Because the focus on C-related features of an action is necessary to improve its efficiency (and frequently to reach the goal at all), these action features are typically salient for the actor. Observers, however, not being responsible for an efficient action execution, focus on the actor's $\mathrm{C}$ to a lower degree (unless they approach actors with a specific interest in their abilities, such as when making employment decisions). Instead, they focus on the actor's goal because its identification is crucial for the understanding of what this actor is doing and for drawing inferences about his or her traits (many of which are themselves goal-based categories, as shown by Read, Jones, \& Miller, 1990). Therefore, actors should interpret their own behaviour in $\mathrm{C}$ rather than $\mathrm{M}$ terms, but observers should prefer $\mathrm{M}$ interpretation of the same behaviour.

These hypotheses received support in several studies. In one experiment (Wojciszke, 1994, Study 1) participants interpreted identical actions encodable both in $\mathrm{C}$ and $\mathrm{M}$ terms (instances of the four types listed in Table 2) but were instructed to take either the actor's or the observer's perspective. For example, they received a description of an event where an employee ingratiated herself with her boss but did it in such a blatant way that it infuriated the boss (a case of sinful failure). The participants were to evaluate this action from the perspective of the actor (employee) or the 
observer (boss) and to write down the rationale for their evaluation. The rationales were later rated by one pair of judges for the degree to which each referred to competence (i.e., that it was clumsy, transparent, and socially unskilled) and another pair rated the rationale for the degree to which it referred to morality (i.e., that it was a sycophantic and insincere act of ingratiation). These ratings of rationale served as the index of behaviour construal. As can be seen in Figure 2, a strong crossover interaction between the perspective and construal content was found. Within the actor perspective, the rationales referred to a much higher degree to $\mathrm{C}$ than $\mathrm{M}$, but within the observer perspective the opposite was true.

The weakness of this study was that participants only imagined their responses in hypothetical situations that were described to them. Therefore we also conducted a correlational study where participants recollected and interpreted real-life episodes that had led them to strong evaluations of themselves or others (Wojciszke, 1994, Study 2). The analysis of rationales of these evaluations showed a pattern similar to that depicted in Figure 2 (independently of whether the recollected episode had led to a positive or negative evaluation). Both studies showed that the actor perspective resulted in a preference for $\mathrm{C}$ over $\mathrm{M}$ construal but the opposite was true for the construal of identical or similar actions from the observer perspective. Interestingly, the tendency to give priority to $\mathrm{M}$ over $\mathrm{C}$ information (at the observer perspective) is so deep-rooted that it appears automatic. Using the

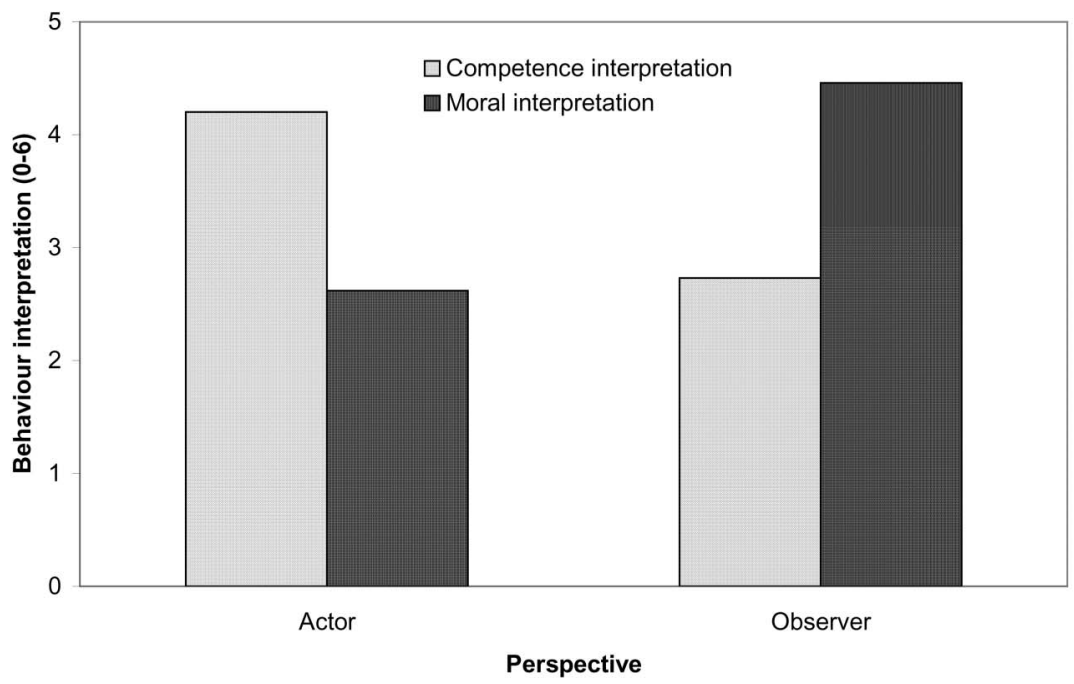

Figure 2. Competence and moral interpretation of behaviour in the actor and the observer perspective (Wojciszke, 1994). 
Stroop paradigm, Wentura, Rothermund, and Bak (2000) showed a greater interference (slower colour-naming times) in naming the colour of a word flashed on a screen when the word denoted an other-relevant trait (or otherprofitable, like pushy or kind) compared to self-relevant words (like onesided or intelligent).

\section{Global evaluative impressions}

The self-interest notion also leads to a prediction that attitudes towards other persons should be more strongly influenced by information on their morality than competence. Even if $\mathrm{C}$ and $\mathrm{M}$ descriptive trait names are equally saturated with evaluative meaning (i.e., balanced in their out-ofcontext valence or favourability), the information on others' $M$ should influence evaluative impressions to a higher degree because it is more directly relevant for the perceiver's self-interest than the information on others' C. This hypothesis was tested in a study where participants gave global impressions of 20 persons from their own social milieu and described them with $10 \mathrm{M}$ and $10 \mathrm{C}$ traits (Wojciszke et al., 1998a). As predicted, global impressions appeared to be more influenced by specific judgements of $\mathrm{M}$ than $\mathrm{C}$ traits. Although the two sets of traits were carefully balanced for their favourability, regression analyses performed separately for each participant showed that moral trait ascriptions predicted a greater portion of global evaluation variance $(53 \%$ on average) than ascriptions of $\mathrm{C}$ traits $(29 \%)$.

This study was correlational, therefore we also conducted an experiment where behavioural information on fictitious target persons was varied factorially in a 2 (moral-immoral) $\times 2$ (competent -incompetent) factorial design. That is, participants received such descriptions of behaviour as Bob defended an absent friend against groundless accusations, but he spoke in such an illogical and obscured way that he could not persuade anybody (a Mpositive/C-negative combination), or Although himself in a hurry, Andrew stopped on his way on meeting a helpless woman; he right away found what was wrong with her car and got it going using an ingenious trick (a M-positive/ C-positive combination). Although both types of information influenced global impressions, morality yielded a much stronger effect $\left(\eta^{2}=.95\right)$ than competence $\left(\eta^{2}=.41\right)$. Moreover, when $\mathrm{M}$ information was negative, the global impressions were always negative, even when the $\mathrm{C}$ input information was positive; but when $\mathrm{M}$ information was positive, the impressions were always positive, as can be seen in Figure 3 .

Interestingly, when the target's behavioural acts were immoral, competence led to a significantly more negative impression than incompetence, presumably because the former means a higher efficiency in wrong-doing (as in the case of a thief or a con-man-such a person is more harmful when 


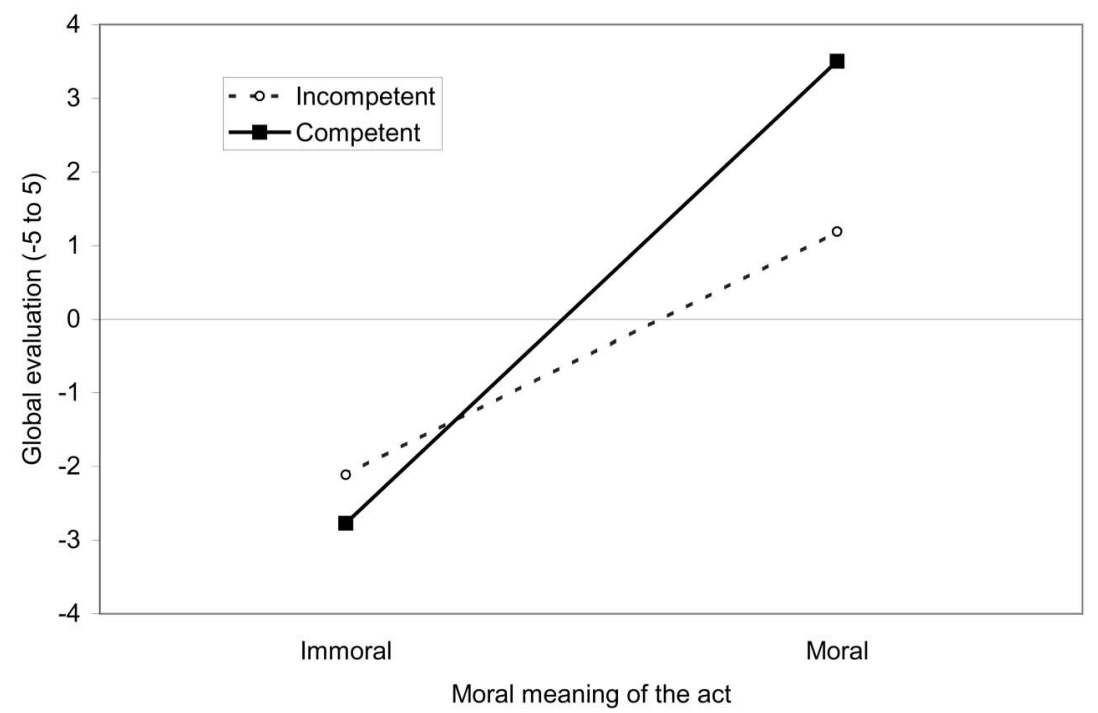

Figure 3. Global evaluations of a person whose behavioural acts were moral vs immoral and competent vs incompetent (Wojciszke et al., 1998a).

competent rather than incompetent). This suggests that evaluative implications of $\mathrm{M}$ information are strong and invariant, while evaluative implications of $\mathrm{C}$ information are much weaker and depend on the accompanying $\mathrm{M}$ information. The moral meaning of an act can radically change evaluative implications of an accompanying competence, but not the other way around. Efficiency has positive implications when accompanying moral acts but it acquires negative meaning when accompanying wrongdoing. Immorality, however, is always negative (and morality positive), the amount of accompanying competence notwithstanding (see Peeters, 1992, for a similar argument).

Altogether, this series of studies showed that the descriptive content of input information plays an important role in shaping global evaluations, above and beyond the influences of a merely evaluative meaning (in contrast to the traditional cognitive algebra approach, which assumes that evaluative meaning of input information is processed independently of its descriptive content). Several other authors have also found that global evaluation depends to a higher degree on M- than C-related information (De Bruin \& Van Lange, 1999; Martijn, Spears, Van der Pligt, \& Jakobs, 1992; Vonk, 1996).

Although impressions of others are more strongly influenced by information on $\mathrm{M}$ than $\mathrm{C}$, this regularity should be context-sensitive. The 


\section{2}

self-interest notion suggests a prediction that this regularity should cease to be true when the target's $C$ contributes to the perceivers' well-being as much as their own abilities do, as in the case of competence of "my lawyer" or "my boss". In such a case, global impressions of others should resemble selfevaluations-i.e., both should depend to higher extent on C than M. To test this hypothesis we studied employees' perceptions of their supervisors in two organisations (Wojciszke, Baryla, \& Mikiewicz, 2004). One was an efficiency-oriented organisation - a competitive financial business where employees' outcomes increase with the competence of their supervisor. Another was a bureaucratic organisation (an institution of the state financial administration) where competence of the boss does not contribute to employees' outcomes (in Poland salaries in such organisations depend on bureaucratic criteria rather than efficiency, so the competence of a boss may be a source of troubles rather than benefits for his or her underlings). In both organisations employees rated seven moral and seven competence traits of their supervisors as well as showing their global evaluations of them.

As can be seen in Table 4, both $\mathrm{C}$ and $\mathrm{M}$ perceptions contributed to global evaluations of supervisors in both organisations. However, contribution of competence was higher in the business (.61) than the bureaucratic (.29) organisation, while the opposite was true for the contribution of perceived morality (.35 and .63 respectively). Both these differences proved reliable as evidenced by significant interaction terms (morality $\times$ organisation

TABLE 4

Employees' ratings of the supervisors morality and competence as predictors of their global evaluations in two organisations

\begin{tabular}{|c|c|c|}
\hline \multirow[b]{2}{*}{ Predictor } & \multicolumn{2}{|c|}{ Organisation/sample } \\
\hline & $\begin{array}{l}\text { Business } \\
(N=79)\end{array}$ & $\begin{array}{c}\text { State administration } \\
\qquad(N=82)\end{array}$ \\
\hline \multicolumn{3}{|c|}{ Perceived competence } \\
\hline$B\left(B_{11}-B_{\mathrm{ul}}\right)$ & $.37(.26 .48)$ & .17 (.08 .26) \\
\hline$\beta$ & $.61^{* * *}$ & $.29 * * *$ \\
\hline \multicolumn{3}{|c|}{ Perceived morality } \\
\hline$B\left(B_{11}-B_{\mathrm{ul}}\right)$ & $.22(.11 .33)$ & $.34(.25 .42)$ \\
\hline$\beta$ & $.35 * * *$ & $.63^{* * *}$ \\
\hline$R^{2}$ (adjusted) & .63 & .67 \\
\hline
\end{tabular}

Each column presents results of a separate (simultaneous) regression analysis.

$B$ unstandardised coefficient with a $95 \%$ confidence interval $\left(B_{11}=\right.$ lower limit; $B_{\mathrm{ul}}=$ upper limit); $B$ standardised coefficient.

${ }^{*} p<.05 .{ }^{* *} p<.01 .{ }^{* * *} p<.001$.

From Wojciszke et al. (2004). 
and competence $\times$ organisation) in a simultaneous regression performed jointly on data from both organisations. The analysis of confidence intervals of unstandardised coefficients shown in Table 4 also corroborates that within the business organisation the perceived competence is a stronger predictor of attitude towards the boss than his or her perceived morality, while the opposite is true in the bureaucratic organisation. Altogether, the dominance of morality over competence in evaluation of other persons becomes reversed when the perceiver's fate depends directly on other person's competence. In such a case, competence dominates over morality, which is typical for self-perceptions as discussed below.

The self-interest logic predicting the dominance of $\mathrm{M}$ over $\mathrm{C}$ information in the perception of others also leads to a prediction of dominance of $\mathrm{C}$ over $\mathrm{M}$ in self-perception. Some initial support for this thesis was obtained in a study where participants interpreted behaviours construable in both $\mathrm{M}$ and C terms (cf. Figure 2). When participants imagined that it was their own behaviour or reconstructed the interpretations of persons who performed the behaviour, its construal was based much more on C (efficiency of the goal-attainment) than $\mathrm{M}$ (moral content of the goal) considerations. Similar increases in C-related interpretations of ambiguous behaviour were observed after priming the perspective of self rather than that of other people. Wojciszke (1997, Study 2) provided his participants with a Rokeachtype measure of instrumental values including both $\mathrm{M}$ and $\mathrm{C}$ traits and asked them to rank them in terms of importance either in self (self-hierarchy of values) or in other people (other-hierarchy of values). Those participants in whom self had been primed (as evidenced by $\mathrm{C}$ values reaching a higher position in the value hierarchy) showed a higher tendency to construe ambiguous behaviour in C-related terms than participants who had worked on other-hierarchy of values.

In the self-perception domain, the closest parallel to global evaluations of others is self-esteem (which is understood here as an affective response towards the self, whereas perceived self-competence and self-morality are understood as important but more specific parts of self-concept). To complete the argument that $\mathrm{C}$ dominates self-attitudes, just as $\mathrm{M}$ dominates interpersonal attitudes, self-esteem should be shown to depend to a higher degree on $\mathrm{C}$ than $\mathrm{M}$ information. To test this hypothesis, six samples were asked for self-ascription of seven $\mathrm{M}$ traits (fair, good, honest, loyal, selfless, sincere, truthful) and seven $\mathrm{C}$ traits (clever, competent, efficient, energetic, intelligent, knowledgeable, logical). These traits were carefully balanced for favourability and the degree of $\mathrm{M}$ - vs C-relatedness. In addition, participants completed various measures of self-esteem. In three samples it was Rosenberg's scale of trait self-esteem; in one sample the Narcissism Personality Inventory, the most frequently used measure of narcissism (Raskin \& Hall, 1979); in one sample a measure of state self-esteem 


\section{WOJCISZKE}

(Heatherton \& Polivy, 1991); and in one sample the preference of own initials over other letters of the alphabet was used as an implicit measure of self-esteem (Koole \& Pelham, 2003). Despite the differentiation of selfesteem measures and samples studied, the results converged in showing a higher prediction of self-esteem by $\mathrm{C}$ than $\mathrm{M}$ self-ascription. Indeed, moral trait ascriptions did not predict self-esteem at all, as can be seen in Table 5 .

The lack of correlation between self-ascription of $\mathrm{M}$ and self-esteem is not at odds with the well-documented Muhammad Ali effect-a tendency to ascribe to oneself morality to a higher degree than competence (Allison, Messick, \& Goethals, 1989), probably because M is seen as more strongly related to the general value of a person than C (Van Lange \& Sedikides, 1998). The Muhammad Ali effect refers to the relative levels of M- and

TABLE 5

Mean self-evaluations of moral- and competence-related traits and their $\beta$ values as predictors of various indices of self-esteem in six samples (regression analyses).

\begin{tabular}{|c|c|c|c|}
\hline & Mean & $S D$ & $\beta$ \\
\hline \multicolumn{4}{|c|}{ Students $(N=153)$, dependent: Trait self-esteem } \\
\hline Moral traits & 5.39 & 0.71 & .05 \\
\hline Competence traits & 4.84 & 0.90 & $.53^{* * *}$ \\
\hline$t$ (difference) & $5.97 * * *$ & & \\
\hline \multicolumn{4}{|c|}{ Employees $(N=162)$, dependent: Narcissism } \\
\hline Moral traits & 5.52 & 0.82 & -.06 \\
\hline Competence traits & 5.12 & 0.76 & $.45^{* * *}$ \\
\hline$t$ (difference) & $5.54 * * *$ & & \\
\hline \multicolumn{4}{|c|}{ Employees $(N=89)$, dependent: State self-esteem } \\
\hline Moral traits & 5.76 & 0.82 & -.13 \\
\hline Competence traits & 5.48 & 0.73 & $.36^{* * *}$ \\
\hline$t$ (difference) & $3.26^{* *}$ & & \\
\hline \multicolumn{4}{|c|}{ Students $(N=88)$, dependent: Implicit self-esteem } \\
\hline Moral traits & 48.45 & 22.10 & -.05 \\
\hline Competence traits & 36.18 & 19.68 & $.38^{* * *}$ \\
\hline$t$ (difference) & $4.00^{* * *}$ & & \\
\hline \multicolumn{4}{|c|}{ Dutch students $(N=120)$, dependent: Trait self-esteem } \\
\hline Moral traits & 5.59 & 0.59 & .03 \\
\hline Competence traits & 5.23 & 0.60 & $.50 * * *$ \\
\hline$t$ (difference) & $5.43 * * *$ & & \\
\hline \multicolumn{4}{|c|}{ Colombian students $(N=60)$, dependent: Trait self-esteem } \\
\hline Moral traits & 5.63 & 0.75 & -.07 \\
\hline Competence traits & 5.51 & 0.75 & $.67 * * *$ \\
\hline$t$ (difference) & 1.35 & & \\
\hline
\end{tabular}

Self-ratings on a scale ranging from 1 to 7 with 4 being the middle point (with the exception of the Implicit self-esteem sample, where the ratings were made on $100 \mathrm{~mm}$-long graphic scales). ${ }^{*} p<.05,{ }^{* *} p<.01,{ }^{* * *} p<.001$.

From Baryla \& Wojciszke (2005). 
C-trait ascription, not to their relation with self-esteem. Moreover, as can be seen from $t$ tests in Table 5, the $\mathrm{M}$ ascription was reliably higher than $\mathrm{C}$ ascription (i.e., the Muhammad Ali effect was found) in five of six samples studied. Still, self-ascribed morality did not correlate with self-esteem, although the self-ascribed competence did.

One obvious explanation of this pattern would be in terms of a ceiling effect - perhaps all people ascribe themselves $M$ traits to such a high extent that there is lack of variability in the $\mathrm{M}$ self-ascription and, therefore, lack of covariability with anything else, self-esteem included. A similar methodological explanation would be in terms of a restricted range of $\mathrm{M}$ judgements-perhaps ascription of morality is restricted to positive judgements while ascriptions of competence include both negative and positive judgements, making them more influential with respect to global evaluative responses. However, in none of the samples was the variance of $\mathrm{M}$-ascription significantly smaller than the variance of C-ascription (cf. standard deviations shown in Table 5). Moreover, in all samples the average $\mathrm{M}$-ascriptions were more than one standard deviation below the maximum, rendering the explanation in terms of the ceiling effect implausible. Finally, in five of six samples nearly all individual self-ratings of both morality and competence were clearly positive (in the exceptional implicit self-esteem sample the majority of both $\mathrm{M}$ and $\mathrm{C}$ self-judgements were neutral because these judgements were indexed with differences between positive and negative traits ascribed to self). This renders the differential range of judgement variability implausible as an explanation.

Another alternative explanation could be formulated in terms of cultural values. The stronger relation between competence and self-esteem may reflect not individual functioning but rather an individualistic cultural norm that prescribes putting more weight on efficiency than virtue or morality, which is valued to a higher extent in collectivistic societies (Schwartz 1992). Since competence is a typical agentic quality and such qualities are highly valued in individualistic societies, they probably constitute the core of an individualistic self-identity, and this may explain why self-esteem appears in our research so strongly correlated with self-perceived competence. But is Poland an individualistic society? According to the 1995-1997 World Values Survey which covered 51 countries, Poland ranked in the middle of individualism-collectivism dimension (Elliot \& Jambor, 2004). This makes Polish samples not very suitable for testing explanations that involve the individualism-collectivism dimension. Therefore, we recruited two other student samples - one from the Netherlands, a very individualistic country, and another from Colombia, an extremely collectivistic country. As can be seen in lower panels of Table 5 , both these samples produced result patterns that were similar to each other and to the already described results of Polish samples. This is clearly discrepant with the cultural explanation. 
Moreover, the "individualistic identity" notion cannot explain the whole pattern of results reported here. If individualistic culture shaped the selfidentity and made competence a more important constituent of the self than morality, the same should also be true of representations of other persons, especially ingroups. Several lines of research show that representation of self and ingroups are closely interlinked: There is a substantial overlap between representations of the self and a typical ingroup, close others and ingroups are included into self, and self serves the function of a default representation of an ingroup (Forgas \& Williams, 2002). All this suggests that what is highly valued in the self should also be important in others. If $\mathrm{C}$ is important in individualistic societies, it should heavily influence both the selfperception and perception of others; if $\mathrm{M}$ is unimportant it should influence both weakly, if at all. This is not what was found in the present researchactually, competence appeared very important in self-perception but morality was crucial in the perception of others.

The findings of Table 5 are correlational and, therefore, we attempted to replicate them in a more experimental way (Baryla \& Wojciszke, 2005). We asked our participants for global evaluations of either themselves or another specific person ("an average person who is not your close friend") filling the Rosenberg self-esteem scale worded as originally or reworded in the way suitable for measuring global evaluations of other persons. Immediately before making their global evaluations participants were asked to recollect and describe in writing an episode involving either the self or the target person. The content of the episode varied inter-individually in a 2 (negative vs positive valence) $\times 2$ (competence vs morality domain) design-i.e., participants described their own (or another person's) failure vs success or moral vs immoral behaviour. As can be seen in Figure 4, the valence of competence memories significantly influenced both self- and other-evaluations (although the former to a lesser extent, which is understandable for a variety of reasons). On the other hand, moral memories influenced only other-evaluations. If anything, self-evaluations (self-esteem) tended to be higher after the negative than positive recollections about self (although this difference was only marginally significant).

Most experimental studies on state self-esteem have used competence information (on successes vs failures) as a manipulation of self-esteem (see Sedikides \& Strube, 1997). Only a small number of studies varying information on social exclusion seem to be an exception to this rule (Leary, 2002). The present notion of competence dominance in self-perception accounts for this apparent efficiency of manipulating self-esteem with the competence information, as well as helping to understand the inefficiency of other manipulations, especially those involving information on morality. The lack of relation between self-ascription of morality and self-esteem is perplexing and obviously in need of further research. Still, the main pattern 


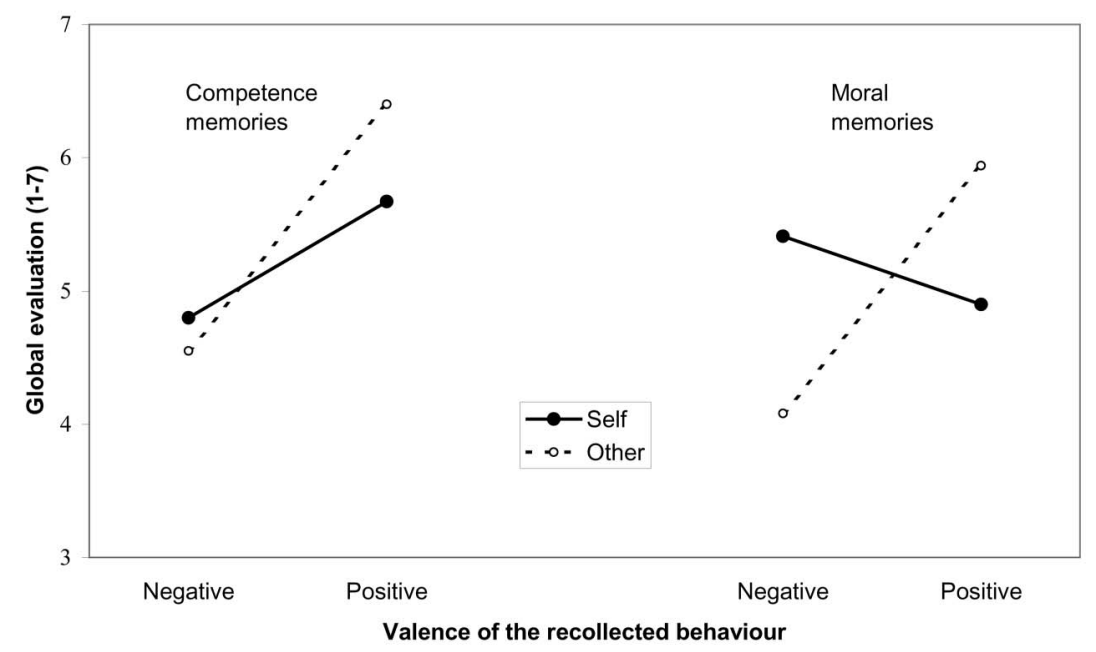

Figure 4. Mean global evaluation of self or other person after competence- or morality-related recollections (Baryla \& Wojciszke, 2005).

of findings presented in Table 5-that $\mathrm{C}$ ascription is more strongly related to self-esteem than $M$ ascription - is entirely consistent with the present thesis of dominance of competence in self-perception and self-attitudes.

\section{Emotional responses}

This analysis and data have some interesting consequences for understanding emotions accompanying behavioural acts of the self and others. First, because the same negative acts may be construed in both $\mathrm{M}$ and $\mathrm{C}$ terms, it makes theoretical sense to compare moral transgressions (M) to failures (C). The same is true for positive acts, as identical acts are frequently construable in both $\mathrm{M}$ terms (as norm-maintenance behaviour) and $\mathrm{C}$ terms (as successes). Second, based on the thesis of higher relevance of $\mathrm{C}$ than $\mathrm{M}$ in the actor perspective, it may be predicted that the individual's own behaviour instigates more extreme emotional responses when it pertains to competence rather than morality. Similarly, based on the higher relevance of $\mathrm{M}$ than $\mathrm{C}$ in the observer perspective, it may be predicted that others' behaviour instigates more extreme emotions when it pertains to morality rather than competence.

We tested these predictions in a study where half the participants were asked to recollect an episode in which they had succeeded and to describe the emotional state experienced during this episode (Wojciszke \& Dowhyluk, 2003). Then they were asked to recollect a personal failure 
and to describe their emotional state in that situation. The other half were asked for recollection and description of episodes involving their own moral transgression or virtuous, moral behaviour (the order of recollections was always counterbalanced). These spontaneously generated descriptions of affective states were analysed for the content of emotions listed as well as for general positivity - negativity of the emotional states reported. The emotion descriptors were rated for their valence, which enabled us to compute indices of the mean valence of emotions reported as responses to own or others' successes and failures or moral and immoral acts. These indices were then subjected to analysis of variance.

In the actor perspective (own behaviours) we found a strong interaction between the act valence (positive-negative) and domain $(\mathrm{M}-\mathrm{C}$ ), as illustrated in Figure 5 (upper part). Within the negative acts, a competence recollection (of a failure) instigated more negative emotions than did an immorality memory (a moral transgression), but within the positive acts competence (a success) led to more positive emotions than did a moral act. To summarise, the reported emotions were more extreme when they pertained to own $\mathrm{C}$ than $\mathrm{M}$. As expected, exactly the opposite was true for emotions reported as responses to $\mathrm{C}$ and $\mathrm{M}$ of other people, as can be seen in Figure 5 (lower part). Clearly, our participants reported stronger emotions in response to others' morality (transgressions and moral acts) than others' competence (failures and successes). Since attitudes (including self-attitude, i.e., self-esteem) are basically affective phenomena, this pattern of data helps to explain why self-ascribed competence is more strongly linked to self-esteem than self-ascribed morality: Own competence fosters stronger affective responses than own morality. However, others' competence induces weaker affect than others' morality and, in effect, the latter influences interpersonal attitudes to a higher extent.

A comparison of the upper and lower parts of Figure 5 shows not only differential interactions between the perspective (self vs others) and domain (M vs $\mathrm{C}$ ), but also much lower extremity of the responses to behaviour of others (compared to own behaviour). Content analyses of the reported emotions showed that this was because of ambivalent responses towards others' behaviour, especially acts pertaining to competence. Responses to others' failures included both negative (dismay, sadness, helplessness) and positive (satisfaction, joy, relief) emotions. Similarly mixed were responses to others' successes (envy, sadness, joy, optimism).

However, the "other" category is very indeterminate, and obviously emotions instigated by another person's behaviour depend on who exactly the other is. Especially, our own attitude towards the other should make an important difference, as predicted by classical theories of cognitive consistency or more recent theorising about motivations underlying the process of hypothesis testing and affective responses to hypothesis 


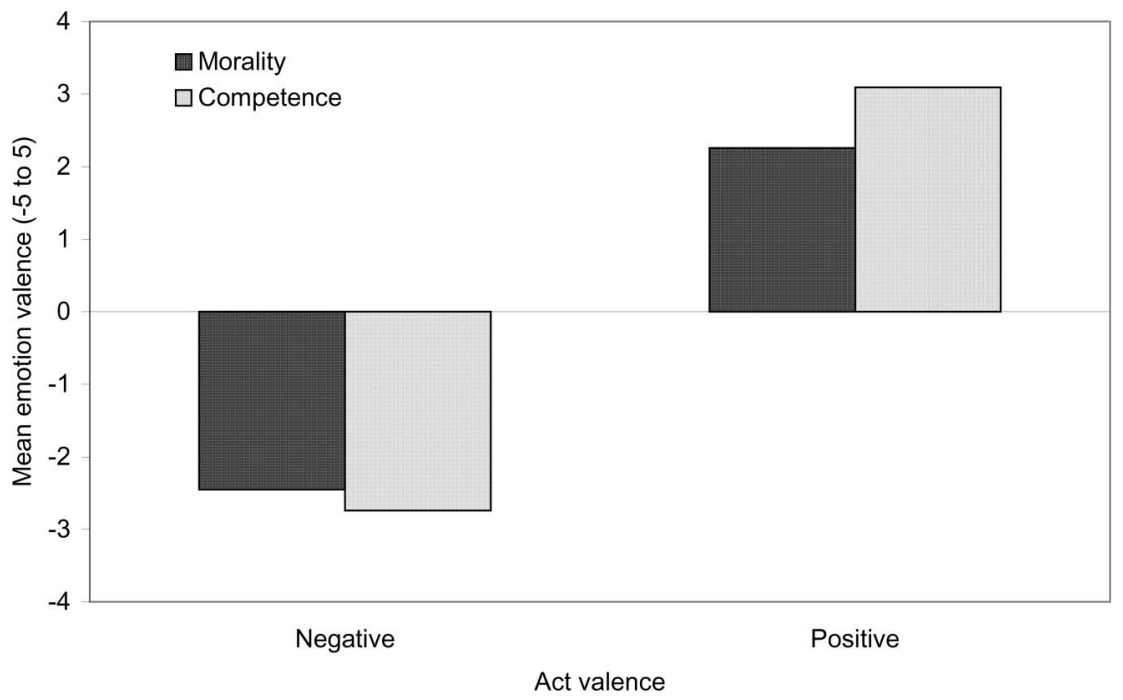

Others' behaviour

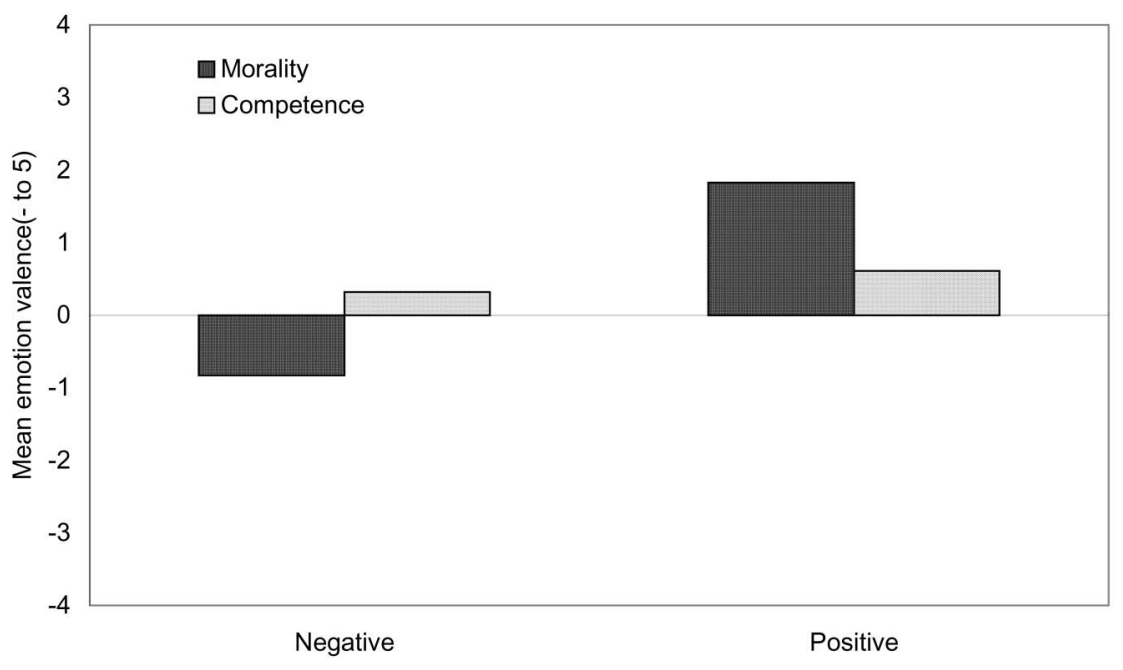

Act valence

Figure 5. Mean valence of emotions reported as responses to own (upper panel) or others' (lower panel) negative or positive acts related to morality or competence (Wojciszke \& Dowhyluk, 2003). 
confirmation - disconfirmation (see Kunda, 1999; Moskowitz, 2005). Emotions induced by positive acts (successes and moral acts) should be more positive when the acts are committed by those whom we like rather than dislike. This is because positive acts committed by the former maintain cognitive consistency and confirm our attitude-based expectancies (which results in additional positivity of emotional response), whereas the same acts committed by a disliked person introduce discomforting imbalance or dissonance and disconfirm our expectancies. By the same logic, emotions induced by negative acts of others (failures and moral transgressions) should be more negative when the acts are committed by those whom we like rather than dislike.

To test these predictions we performed another series of studies using a similar method, but this time asking for recollection of episodes and reporting of emotions instigated by actions of another person who was either liked or disliked by the participants (Wojciszke \& Szymkow, 2003). As can be seen in Figure 6, the pattern of results appeared strikingly different for $\mathrm{C}$ and $\mathrm{M}$ domains. Emotional responses to others' successes and failures depended solely on whether the other was liked or disliked. The success of another person seems not to have any inherent positive value-it instigates positive emotions when we like the person, but it brings negative responses when the person is disliked. The failure of others is a simple inversion of this pattern. So, the way our own self and attitudes are implicated rests entirely on affective responses to competence of others.

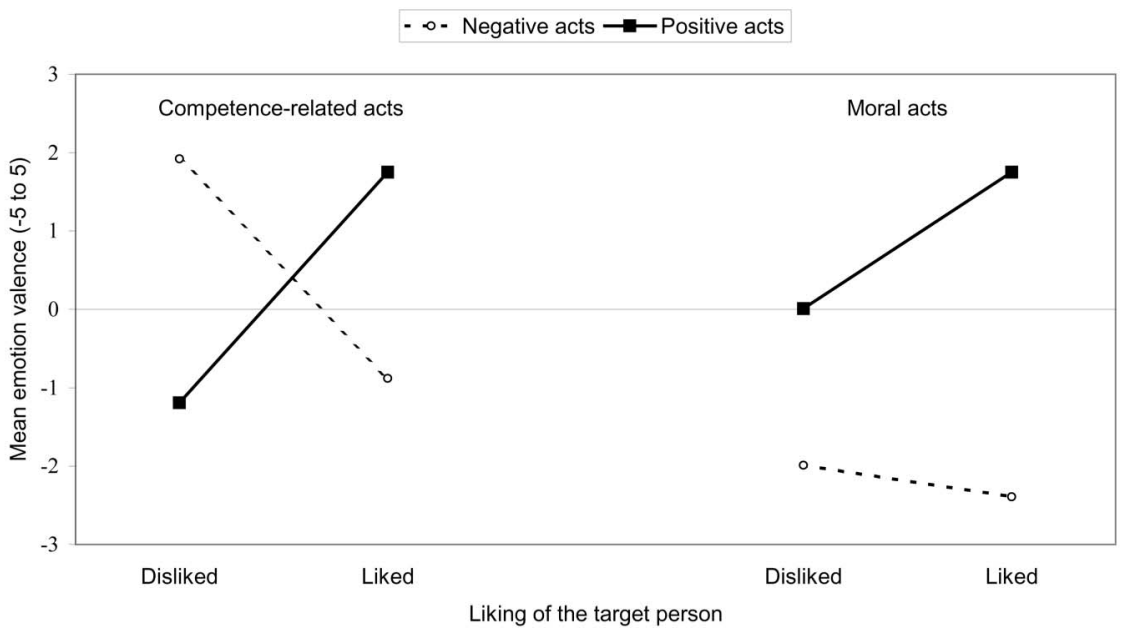

Figure 6. Mean valence of emotions reported as responses to competence-related and moral acts committed by a person who was liked or disliked by the participants (Wojciszke \& Szymków, 2003). 
The story is quite different for the moral domain. Moral transgressions always led to negative emotions, independently of who committed them, but positive moral acts led to positive emotions only when performed by persons liked by the participant. When the person was disliked, responses were strongly ambivalent, including both satisfaction and dissatisfaction, surprise, and, especially, uncertainty/doubt. As many as $28 \%$ of participants used the latter term to describe their emotional state after moral acts of a disliked person, compared to only $5 \%$ who responded in this way to a moral act by a person whom they liked. So, whereas immoral behaviour is inherently negative, moral behaviour is very ambiguous because it involves acting in the perceiver's interests and this may be perceived as underlain by ulterior motives such as ingratiation (Jones, 1990) or as attempts to induce unwanted feelings of indebtedness and obligation to repay the favour in future (Cialdini, 2001). Interestingly, the perceiver's own attitude towards the actor serves as a strongly disambiguating factor.

To summarise, the general pattern of emotional responses to own and others' behaviour showing the two types of content paralleled the pattern reported previously for attitudinal responses. People seem to care much more about others' (im)morality than (in)competence, but the opposite is true for responses to their own (im)morality and (in)competence.

\section{CONCLUDING REMARKS}

The reviewed results show clearly that morality-immorality of others matters to a perceiver to a much higher degree than their competence. When forming global evaluations of others, the perceiver is more interested in their moral- than competence-related qualities, construes their behaviour in moral terms, and his or her impressions and emotional responses are more strongly based on moral- than competence-related considerations. Just the opposite tends to be true for self-perception and self-attitudes. Own behaviours are construed more readily in terms of competence than morality, and own competence influences self-evaluations and emotional responses to a higher extent than own morality. These regularities were found convergently despite divergence in designs, measures, and samples.

The presented differences in processing of moral and competence information were predicted and explained in terms of differential relevance of the two types of content for perceiver self-interest. Because self-interest is differently implicated in the actor vs observer perspective, this notion also provides a parsimonious account of the striking differences in the way in which morality and competence are involved in perception of self and others. Interestingly, the reversal of morality-competence differences in self-perception compared to the perception of others probably cannot be explained in merely cognitive terms, such as the differential trait-behaviour 
implications or asymmetry in the diagnostic value of positive and negative behaviour. It would be strange to assume that the structure of such categories as honesty or intelligence varies depending on whether the categories are applied to self or to other people. However, self-other differences may be explained in terms of the present assumption that selfinterest is differently implicated in the actor vs observer perspective.

\section{Actor vs observer or agent vs recipient}

The present results shed a new light on the classical actor-observer difference in perspective with actors attributing their own behaviour to situational factors and observers preferring dispositional attributions of others' behaviour (Jones \& Nisbett, 1971). This difference has been widely accepted, although its actual generality and empirical support is more modest than is usually believed (see Robins, Spranca, \& Mendelsohn, 1996; Watson, 1982). The actor-observer distinction has continued to inspire research over the 30 years since its introduction (e.g., Kruger \& Gilovich, 2004; Malle \& Pearce, 2001; Storms, 1973). Nevertheless it tended to remain a relatively isolated effect - just another item on the long list of cognitive biases (cf. Moskowitz, 2005). It has never acquired the prominence it deserves considering its ubiquity in social interaction (there is always an actor and an observer in social exchanges) and large differences in the way people perceive themselves and others (Pronin, Gilovich, \& Ross, 2004). One reason for this relative under-utilisation of the actor-observer difference may be its narrow conceptualisation as a merely cognitive difference in perspective with effects restricted to attribution patterns.

The present theorising stresses the crucial role of interests and suggests possible motivational underpinnings of actor-observer differences. It can be hypothesised that the actor perspective is basically a standpoint of an agent performing a behaviour, whereas the observer perspective is a standpoint of $a$ recipient at whom the behaviour is directed (actually or potentially). In effect, the actor perspective is not constrained to perceiving one's own behaviour, neither is the observer perspective limited to the perception of others.

Indeed, the agent perspective may also be assumed in perceiving behaviour of others when they are interdependent (see Rusbult \& Van Lange, 2003) or symbiotically related to the perceiver. A symbiotic selfother relation occurs when interests of the perceiver and others are synergic (mutually supportive) or identical. This may happen in at least three ways. One is the self-extension or assimilation when others become so close that they are psychologically included in the self, as happens in close relationships. When a partner is perceived as a part of one's self, his or her characteristics become undistinguishable from the perceiver's own qualities, 
the actor-observer perspective differences are lessened, and the tendency to benefit oneself with money to a higher extent than the partner diminishes sharply (Aron, Aron, Tudor, \& Nelson, 1991). The second way is identification or accommodation, when the self is adjusted to another person or social entity in such a way that the perceiver endorses and adopts the entity's goals. This happens when people identify with significant others (my President), representatives of their group (my national team), or persons who are admired for one reason or another (e.g., a heroine of my beloved soap opera). The third way to a symbiotic self-other relation is vicarious agency, which is a special case of interdependence where another person acts as an agent carrying out the perceiver's goals (e.g., my lawyer or my plumber).

Probably, whenever a target is symbiotically related to the perceiver, the former is perceived in a way that is typical for self-perception, because other's interests become indistinguishable from self-interests of the perceiver. In line with these speculations, the actor-observer difference in attribution disappears in the perception of close others - a fact that is well known but not well understood (cf. Green, Lightfoot, Bandy, \& Buchanan, 1985). The present theorising leads to further hypotheses that the same should also be true for persons with whom perceivers identify themselves or who are vicarious agents. Moreover, the perception and evaluation of symbiotic others should be dominated by information about competence, not morality.

On the other hand, if the observer perspective is basically the standpoint of a person who is on the receiving end of actions, it may be expected that sometimes one's own behaviour is also seen in this way. First, when own action is directed at symbiotic others because these are persons whose interests are easily taken into account by the actor. Second, own actions may be seen in the recipient-relevant categories when perceived from a temporal distance: under the deliberative mindset (Gollwitzer, 1996) before action, when the decision about engagement is still being made, or during a post-agentic reflection on an action that is already completed.

For several reasons, it may be more feasible to talk about the agentrecipient rather than the actor-observer difference in perspective. First, the latter distinction equates the actor with self, and this seems to be an untenable position because in numerous instances the behaviour of others is treated in exactly the same way as the perceiver's own. Second, the actorobserver distinction equates observer's perceptions with the perception of any other person's behaviour. The "other" category is, obviously, very indeterminate and various "others" may be perceived in different ways depending on the relation between them and the perceiver. Specifically, as discussed previously and shown by results presented in Table 4, 


\section{WOJCISZKE}

symbiotically related others may be perceived in much the same way as the self is perceived. The agent-recipient distinction may be theorised about in a more dynamic and context-dependent way than the actor-observer difference, which seems to be strictly positional.

\section{Content matters}

Finally, the present programme of research stresses the crucial role of content in social information processing. Many years ago, Rothbart and Park (1986) insisted that "not all traits were created equal", showing empirically that that was indeed the case. Still, most social cognition research (from classical impression formation to modern studies on knowledge accessibility) has tended to treat information content as merely a source of error variance requiring replications over the content to obtain general regularities of social perception.

The present line of research shows that content does matter and its effect should be systematically pursued rather than averaged and ignored. Moral and competence information is differently processed in the perception of both self and others. Some of these differences are dramatic and involve reversals of the regularities found empirically. Averaging over these two types of content may have no more sense than averaging the number of legs of a horse and a rider. And this poses a challenge to social cognition researchers-how to include the content of processed information into social cognition theorising.

\section{REFERENCES}

Allison, S. T., Messick, D. M., \& Goethals, G. R. (1989). On being better but not smarter than others: The Muhammad Ali effect. Social Cognition, 7, 275-296.

Aron, A., Aron, E. N., Tudor, M., \& Nelson, G. (1991). Close relationships as including other in the self. Journal of Personality and Social Psychology, 60, 241-253.

Bandura, A. (1997). Self-efficacy: The exercise of control. New York: Freeman.

Bargh, J. A. (1997). The automaticity of everyday life. In R. S. Wyer Jr. (Ed.), The automaticity of everyday life: Advances in social cognition (Vol. 10, pp. 1-61). Mahwah, NJ: Lawrence Erlbaum Associates Inc.

Baryla, W., \& Wojciszke, B. (2005). On the dominance of competence information in the selfconcept. Manuscript in preparation.

Baumeister, R. F., Bratslavsky, E., Finkenauer, C., \& Vohs, K. D. (2001). Bad is stronger than good. Review of General Psychology, 5, 323-370.

Borkenau, P. (1986). Toward an understanding of trait interrelations: Acts as instances for several traits. Journal of Personality and Social Psychology, 51, 371-381.

Brycz, H., \& Wojciszke, B. (1992). Personality impressions on ability and morality trait dimensions. Polish Psychological Bulletin, 23, 223-236.

Caccioppo, J. T., Gardner, W. L., \& Berntson, G. G. (1997). Beyond bipolar conceptualizations and measures: The case of attitudes and evaluative space. Personality and Social Psychology Review, 1, 3-25. 
Chemers, M. M. (2001). Leadership effectiveness: An integrative review. In M. A. Hogg \& R. S. Tindale (Eds.), Blackwell handbook of social psychology: Group processes (pp. 376-399). Oxford: Blackwell Publishers.

Cialdini, R. B. (2001). Influence: Science and practice. New York: Allyn \& Bacon.

De Bruin, E. N. M., \& Van Lange, P. A. M. (1999). Impression formation and cooperative behaviour. European Journal of Social Psychology, 29, 305-328.

Dijksterhuis A., \& Bargh, J. A. (2001). The perception-behavior expressway: Automatic effects of social perception on social behavior. In M. P. Zanna (Ed.), Advances in experimental social psychology. (Vol. 33, pp. 1-40). New York: Academic Press.

Elliot, M., \& Jambor, E. (2004). Culture and distress: When personal and cultural values conflict. Unpublished manuscript.

Fiske, S. T., Cuddy, A. J., Glick, P., \& Xu, J. (2002). A model of (often mixed) stereotype content: Competence and warmth respectively follow from the perceived status and competition. Journal of Personality and Social Psychology, 82, 878-902.

Fiske, S. T., Xu, J., Cuddy, A. J., \& Glick, P. (1999). (Dis)respecting versus (dis)liking: Status and interdependence predict ambivalent stereotypes of competence and warmth. Journal of Social Issues, 55, 473-491.

Forgas, J. P., \& Williams, K. D. (Eds.). (2002). The social self. Cognitive, interpersonal, and intergroup perspectives. New York: Psychology Press.

Gollwitzer, P. M. (1996). The volitional benefits of planning. In P. M. Gollwitzer \& J. A. Bargh (Eds.), The psychology of action (pp. 287-312). New York: Guilford Press.

Green, S. K., Lightfoot, M. A., Bandy, C., \& Buchanan, D. R. (1985). A general model of the attribution process. Basic and Applied Social Psychology, 6, 159-179.

Heatherton, T. F., \& Polivy, J. (1991). Development and validation of a scale for measuring state self-esteem. Journal of Personality and Social Psychology, 60, 895-910.

Jarvis, W. B. G., \& Petty, R. E. (1996). The need to evaluate. Journal of Personality and Social Psychology, 70, 172-194.

Jaworski, M., \& Drogosz, M. (1998). Hamowanie alternatywnej struktury poznawczej jako mediator efektu asymilacji [Inhibition of alternative categories as a mechanism of the assimilation effects]. Przeglad Psychologiczny, 41, 135-150.

Jones, E. E. (1990). Interpersonal perception. New York: W. H. Freeman \& Company.

Jones, E. E., \& Nisbett, R. E. (1971). The actor and the observer: Divergent perceptions of the causes of behavior. Morristown, NJ: General Learning Press.

Jost, J. T., \& Hunyady, O. (2002). The psychology of system justification and palliative function of ideology. In W. Stroebe \& M. Hewstone (Eds.), European review of social psychology (Vol. 13, pp. 111-153). Hove, UK: Psychology Press.

Kanouse, D. E., \& Hanson, L. R. Jr. (1972). Negativity in evaluations. In E. E. Jones, D. E. Kanouse, H. H. Kelley, R. E. Nisbett, S. Valins, \& B. Weiner (Eds.), Attribution: Perceiving the causes of behavior (pp. 47-62). Morristown, NJ: General Learning Press.

Kinder, D. R., \& Sears, D. O. (1985). Public opinion and political action. In G. Lindzey \& E. Aronson (Eds.), Handbook of social psychology (3rd Ed., Vol. 2, pp. 659-741). New York: Random House.

Koole, S. L., \& Pelham, B. W. (2003). On the nature of implicit self-esteem: The case of the name letter effect. In S. Spencer, S. Fein, \& M. P. Zanna (Eds.), Motivated social perception: The Ontario Symposium (Vol. 9, pp. 93 -166). Hillsdale, NJ: Lawrence Erlbaum Associates Inc.

Kruger, J., \& Gilovich, T. (2004). Actions, intentions, and self-assessment: The road to selfenhancement is paved with good intentions. Personality and Social Psychology Bulletin, 30, $328-339$.

Kubicka-Daab, J. (1989). Positivity and negativity effects in impression formation: Differences in processing information about ability and morality dispositions. Polish Psychological Bulletin, 20, 295-307. 
Kunda, Z. (1999). Social cognition. Making sense of people. Cambridge, MA: MIT Press.

Leary, M. (2002). The interpersonal basis of self-esteem. Death, devaluation or deference? In J. Forgas \& K. D. Williams (Eds.), The social self: Cognitive, interpersonal and intergroup perspectives (pp. 143-159). New York: Psychology Press.

Maddux, J. E., \& Gosselin, J. T. (2003). Self-efficacy. In M. R. Leary \& J. P. Tangney (Eds.), Handbook of self and identity (pp. 218-238). New York: Guilford Press.

Malle, B. F., \& Pearce, G. E. (2001). Attention to behavioral events during interaction: Two actor-observer gaps and three attempts to close them. Journal of Personality and Social Psychology, 81, $278-294$.

Martijn, C., Spears, R., Van der Pligt, J., \& Jakobs, E. (1992). Negativity and positivity effects in person-perception and inference: Ability versus morality. European Journal of Social Psychology, 22, 453-463.

Martin, L. L., Strack, F., \& Stapel, D. A. (2001). How the mind moves: Knowledge accessibility and the fine-tuning of the cognitive system. In A. Tesser \& N. Schwarz (Eds.), Blackwell handbook of social psychology: Intraindividual processes (pp. 236-256). Oxford: Blackwell Publishers.

Moskowitz, G. B. (2005). Social cognition. Understanding self and others. New York: Guilford Press.

Peeters, G. (1992). Evaluative meanings of adjectives in vitro and in context: Some theoretical implications and practical consequences of positive negative asymmetry and behaviouraladaptive concepts of evaluation. Psychologia Belgica, 32, 211-231.

Peeters, G., \& Czapinski, J. (1990). Positive-negative asymmetry in evaluations: The distinction between affective and informational negativity effects. In W. Stroebe \& M. Hewstone (Eds.), European review of social psychology (Vol. 1, pp. 33-60). New York: Wiley.

Phalet, K., \& Poppe, E. (1997). Competence and morality dimensions of national and ethnic stereotypes: A study in six eastern-European countries. European Journal of Social Psychology, 27, 703-723.

Pronin, E., Gilovich, T., \& Ross, L. (2004). Objectivity in the eye of beholder: Divergent perceptions of bias in self versus others. Psychological Review, 111, 781-799.

Raskin, R., \& Hall, C. S. (1979). A narcissistic personality inventory. Psychological Reports, 45,590 .

Read, S. J., Jones, D. K., \& Miller, L. C. (1990). Traits as goal-based categories: The importance of goals in the coherence of dispositional categories. Journal of Personality and Social Psychology, 58, 1048-1061.

Reeder, G. D. (1993). Trait-behavior relations and dispositional inference. Personality and Social Psychology Bulletin, 19, 586-593.

Reeder, G. D., \& Brewer, M. B. (1979). A schematic model of dispositional attribution in interpersonal perception. Psychological Review, 86, 61-79.

Reeder, G. D., Pryor, J. B., \& Wojciszke, B. (1992). Trait-behaviour relations in social information processing. In G. Semin \& K. Fiedler (Eds.), Language and social cognition (pp. $37-57)$. Beverly Hills, CA: Sage.

Robins, R. W., Spranca, M. D., \& Mendelsohn, G. A. (1996). The actor-observer effect revisited: Effects of individual differences and repeated social interactions on actor and observer attributions. Journal of Personality and Social Psychology, 71, 375-389.

Rothbart, M., \& Park, B. (1986). On the confirmability and disconfirmability of trait concepts. Journal of Personality and Social Psychology, 50, 131-142.

Rozin, P., \& Royzman, E. B. (2001). Negativity bias, negativity dominance, and contagion. Personality and Social Psychology Review, 5, 296-320.

Rusbult, C. E., \& Van Lange, P. A. M. (2003). Interdependence, interaction and relationships. Annual Review of Psychology, 54, 351-375. 
Schwartz, S. H. (1992). Universals in the content of values: Theoretical advances and empirical test in 20 countries. In M. P. Zanna (Ed.), Advances in experimental social psychology (Vol. 25, pp. 1-65). New York: Academic Press.

Sedikides, C., \& Strube, M. J. (1997). Self-evaluation: To thine own self to be good, to thine own self to be sure, to thine own self to be true, and to thine own self to be better. In M. P. Zanna (Ed.), Advances in experimental social psychology (Vol. 29, pp. 209-269). New York: Academic Press.

Skowronski, J. J. (2002). Honesty and intelligence judgements of individuals and groups: The effects of entity-related behavior diagnosticity and implicit theories. Social Cognition, 20, $136-169$.

Skowronski, J. J., \& Carlston, D. E. (1987). Social judgement and social memory: The role of cue diagnosticity in negativity, positivity, and extremity biases. Journal of Personality and Social Psychology, 52, 689-699.

Skowronski, J. J., \& Carlston, D. E. (1989). Negativity and extremity biases in impression formation: A review of explanations. Psychological Bulletin, 105, 131-142.

Srull, T. K., \& Wyer, R. S. Jr. (1989). Person memory and judgment. Psychological Review, 96, $58-83$.

Storms, M. D. (1973). Videotape in the attribution processes: Reversing actors' and observers' points of view. Journal of Personality and Social Psychology, 27, 165-175.

Tatarkiewicz, W. (1976). Analysis of happiness. Warsaw: PWN Polish Scientific Publishers.

Van Lange, P. A. M. (2000). Beyond self-interest: A set of propositions relevant to interpersonal orientations. European Review of Social Psychology, 11, 297-330.

Van Lange, P. A. M., \& Kuhlman, D. M. (1994). Social value orientations and impressions of a partner's honesty and intelligence: A test of the might versus morality effect. Journal of Personality and Social Psychology, 67, 126-141.

Van Lange, P. A. M., \& Sedikides, C. (1998). Being more honest but not necessarily more intelligent than others: Generality and explanations for the Muhammad Ali effect. European Journal of Social Psychology, 28, 675-680.

Vonk, R. (1996). Negativity and potency effects in impression formation. European Journal of Social Psychology, 26, 851-865.

Vonk, R. (1999). Effects of other-profitability and self-profitability on evaluative judgements of behaviors. European Journal of Social Psychology, 29, 833-842.

Watson, D. (1982). The actor and the observer: How are their perceptions of causality divergent? Psychological Bulletin, 92, 682-700.

Wentura, D., Rothermund, K., \& Bak, P. (2000). Automatic vigilance: The attention-grabbing power of approach- and avoidance-related social information. Journal of Personality and Social Psychology, 78, 1024-1037.

Wojciszke, B. (1994). Multiple meanings of behaviour: Construing actions in terms of competence or morality. Journal of Personality and Social Psychology, 67, 222-232.

Wojciszke, B. (1997). Parallels between competence- versus morality-related traits and individualistic versus collectivistic values. European Journal of Social Psychology, 27, $245-256$.

Wojciszke, B., Baryla, W., \& Mikiewicz, A. (2004). Liking and respect as two dimensions of interpersonal attitudes. Manuscript submitted for publication.

Wojciszke, B., Bazinska, R., \& Jaworski, M. (1998a). On the dominance of moral categories in impression formation. Personality and Social Psychology Bulletin, 24, 12451257.

Wojciszke, B., Brycz, H., \& Borkenau, P. (1993). Effects of information content and evaluative extremity on positivity and negativity biases. Journal of Personality and Social Psychology, $64,327-336$. 


\section{WOJCISZKE}

Wojciszke, B., \& Dowhyluk, M. (2003). Emotional responses toward own and others' behavioural acts related to competence and morality. Polish Psychological Bulletin, 34, $143-$ 151.

Wojciszke, B., Dowhyluk, M., \& Jaworski, M. (1998b). Moral and competence-related traits: How do they differ? Polish Psychological Bulletin, 29, 283-294.

Wojciszke, B., \& Klusek, B. (1996). Moral and competence-related traits in political perception. Polish Psychological Bulletin, 27, 319-325.

Wojciszke, B., \& Szymkow, A. (2003). Emotions related to others' competence and morality. Polish Psychological Bulletin, 34, 135-142.

Wyer, R. S., \& Srull, T. K. (1986). Human cognition in its social context. Psychological Review, 93, 322-359.

Zajonc, R. B. (2000). Feeling and thinking: Closing the debate over independence of affect. In J. P. Forgas (Ed.), Feeling and thinking: The role of affect in social cognition (pp. 31-58). Cambridge: Cambridge University Press. 